IV. Aus dem evangelischen Krankenhause in Witten.

\title{
Kasuistischer Beitrag zur Hysterie der Kinder.
}

Von Privatdozent Dr. Bruno Leick, dirigirendem Arzt der inneren Abtheilung.

In einigen früheren Arbeiten ') habe ich darauf hingewiesen. dass die Hysterie der Kinder durchaus keine so seltene Erkrankung ist, wie man früher allgemein und heute wohl noch theilweise anzunehmen geneigt ist, sowie dass in unserem Zeitalter der Nervosität derartige Erkrankungen $v: n$ Jahr zu Jahr zunehmen werden. Die inzwischen gesammelten Erfahrungen haben mich in dieser Meinung nur bestätigt. Thatsächlich kommen hysterische Affektionen bei Kindern relativ häufig vor, und als selten gelten sie wohl nur deshalb, weil sie so häufig verkannt werden. Und doch ist hier die richtige Diagnose, mehr noch wie bei den meisten anderen Erkrankungen, die erste Vorbedingung. für eine richtige Therapie.

Ein in letzter Zeit beobachteter Fall scheint mir interessant genug, um als kasuistischer Beitrag hier einen bescheidenen Platz zu finden.

Ende Januar erschien in meiner Sprechstunde eine Frau mit ihrem 9 Jahre alten Knaben, um meinen Rath einzuholen, weil der Junge "seit einigen Tagen nicht mehr schreiben könne." Auf näheres Befragen gab die Mutter an, dass ihr zwar stets etwas zarter, sonst aber im allgemeinen gesunder Junge vor sechs Tagen ziemlich plöt\%lich mit Erbrechen und starkem Mattigkeitsgefühl erkrankt sei, angeblich weil das Kind gezwungen worden sei, eine ihm nicht zusagende Suppe zu essen. Am nächsten Tage sei der Kranke unfähig gewesen, zu stehen und zu gehen. Ohne ärztliche Hilfe sei diese "Lühmung im Laufe eines Tages zurückgegangen. Der Junge sei wieder zur Schule geschickt worden, doch habe sich jetzt eine eigenthümliclıe Schreibstïrung gezeigt, die von Tag zu Tag schlimmer geworden sei. Zum Beweise legte mir die Mutter das Schreibheft ihres Sohnes vor. Die Durchsicht desselben ergab thatsächlich eine ganz auffällige Veränderung der Schrift. Während bis zum Tage der Erkrankung die Schrift durchaus normal. für das Alter des Patienten sogar gut erschien, präsentirten sich die nach der Erkrankung angefertigten Schriftproben als ein fast unleserliches Gekritzel, bedeckt mit Klecksen, da die Finger bisweilell die Feder hatten fallen lassen. Man konnte an der Hand des Schreibheftes deutlich eine von Tag zul Tage fortschreitende Verschlechterung der Schrift constatiren.

Mein erster Gedanke war, dass es sich wohl um eine Chorea han- deln möge, doch genügte ein Blick auf den Knaben, um festzustellen, dass choreatische Zuckungen gar nicht, auch nicht andeutungsweise bestanden. Der Junge sah wohl etwas blass aus, im übrigen liess sich nichts Krankhaftes feststellen. Da mir nun die Mutter erzählt hatte, dass am zweiten Tage der Erkrankung eine schnell volübergegangene "Lähmung der Beine" bestanden habe, kam ich auf die Vermuthung, dass eine hysterische Erkrankung vorliegen möge, und beschloss, sogleich die Probe auf das Exempel zu machen.

Ich' liess den Kranken, nachdem ich ihn ermahnt hatte, sich recht zusammen\%unehmen und seine Sache so gut wie möglich zu machen, einen einfachen Satz niederschreiben. Es war ein schlechtes Gekritzel, wie Figur 1 zeigt.

Während des Schreibens sah ich, wie die ganze Hand hin und her zuckte, die Feder einmal den Fingern entfiel Jetzt sagte ich dem kleinen Patienten, ich wolle bei ihm ein Mittel anwenden, welches zwar etwas wehe thun, dafür aber auch sichere Heilung bringen werde. Mit mässig starkem Strome faradisirte ich ca. 2 Minuten lang die Hand. Eine alsdann vorgenommene Schreibübung zeigte eine ganz erhebliche Besserung. Noch einmal zwei Minuten dauerndes Faradisiren, und nun schrieb der Junge so gut wie früher. Figur 2 stellt diese letztere Schriftprobe dar. Die Heilung der seit einigen Tagen bestehenden Störung war also in ca. 5 Minuten erfolgt.

l) B. Leick, Zeitschrift für klinische Medizin Bd. XXX, Heft 5 und 6. - Zeitschrift für praktische Aerzte 1896, No. 20.

Fig. 1.

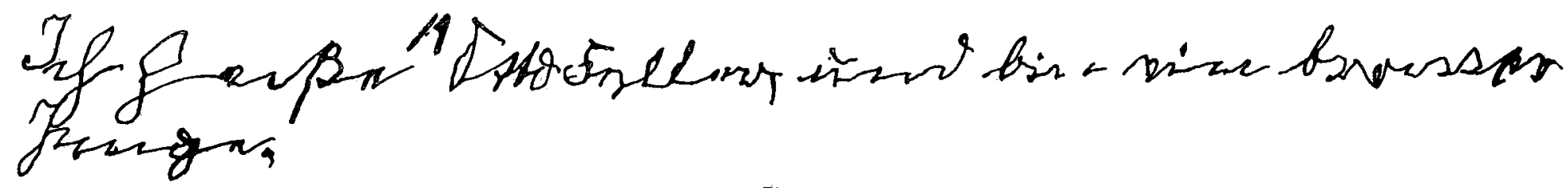

Fig. 2

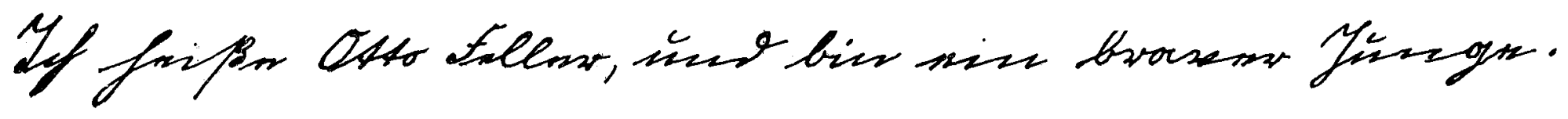


Am nächsten Nachmittage liess ich den Knaben noclı einmal kommen und konnte mich davon überzengen, dass die Heilung von Bestand war.

Den einzigen Einwand, den man im vorliegenden Falle gegen die Diagnose einer hysterischen Erkrankung machen könnte, wäre meines Erachtens der, dass es sich bei meinem kleinen Patienten um bewusste Simulation gehandelt babe. Dies trifft jedoch sicherlich nicht zu. Der einzige Grund für, eine derartige Simulation bei einem 9jährigen Knaben könnte doch nur die Befreiung vom Schulbesuch, resp. von den schriftlichen Arbeiten sein. In unserem Falle hat aber das Kind die Schule weiter besuchen, scine Arbeiten, so gut es eben ging, anfertigen müsseı. A us dem Schreibheft ersah man ferner, wie die Schrift von Tag zu Tage schlechter geworden war, was bei Simulation wohl kaum der Fall gewesen wäre. Schliesslich wäre bei Annahme bewusster Simulation der Erfolg der Therapie garnicht zu verstehen. Ausserdem war die Freude des Kleinen über seine schnelle Heilung eine so offenkundige, dass ich an Simulation nicht glauben kann. 